\title{
Undergraduate Social Entrepreneurship Education and Communication Design
}

\author{
Audrey Barnes \\ Industrial Design \\ James Madison University \\ Harrisonburg, VA 22807 \\ +1 (540) 568-7670 \\ barnesal@jmu.edu \\ Patrice Ludwig \\ Department of Biology \\ James Madison University \\ Harrisonburg, VA 22807 \\ $+1(540) 568-4132$ \\ ludwigpm@jmu.edu
}

\author{
Seán McCarthy \\ School of Writing, Rhetoric \& \\ Technical Communication \\ James Madison University \\ Harrisonburg, VA 22807 \\ +1 (540) 568-7943 \\ mccartsr@jmu.edu
}

\author{
Kevin Giovanetti \\ Department of Physics \\ James Madison University \\ Harrisonburg, VA 22807 \\ +1 (540) 568-6353 \\ giovankl@jmu.edu
}

\author{
Kelsey Robinson \\ School of Writing, Rhetoric \& \\ Technical Communication \\ James Madison University \\ Harrisonburg, VA 22807 \\ +1 (540) 568-6004 \\ robinskr@jmu.edu
}

\author{
Fred Briggs \\ Vektortek LLC \\ 43837 Robindale Ct \\ Ashburn, VA \\ fredmbriggs@gmail.com
}

\begin{abstract}
This experience report examines the role of communication design in a project in which undergraduate students sought to find social entrepreneurial uses for UAV technologies, more commonly known as drones. In particular, the report explores how students used Google Drive to document the design process for their projects, made their work publicly accessible via a WordPress website, and created a public showcase at the end of the semester. Using student and faculty feedback, the report assesses the successes and challenges of these communication strategies, and how faculty plan to improve the overall communication design in further iterations of the course.
\end{abstract}

\section{CCS Concepts}

- Human-centered computing $\rightarrow$ Computer supported cooperative work $\bullet$ Human-centered computing $\rightarrow$ Information visualization • Human-centered computing $\rightarrow$ Social content sharing

\footnotetext{
Permission to make digital or hard copies of part or all of this work for personal or classroom use is granted without fee provided that copies are not made or distributed for profit or commercial advantage and that copies bear this notice and the full citation on the first page. Copyrights for third-party components of this work must be honored. For all other uses, contact the Owner/Author. Copyright is held by the owner/author(s).

SIGDOC '16, September 23-24, 2016, Silver Spring, MD,

USA

ACM 978-1-4503-4495-1/16/09.

httb://dx.doi.org/10.1145/2987592.2987625
}

\section{Keywords}

Social entrepreneurship; UAVs; pedagogy; communication design

\section{INTRODUCTION}

"Social entrepreneurship" is an increasingly important concept in government, philanthropy, and higher education, yet it resists clear definition [1]. For example, the term has been variously used to describe: how nonprofit organizations employ business strategies to attract funding; the creation of businesses to serve lower income demographics; and the practice of using innovation strategies to bring about social change [1]. Despite its vagueness, social entrepreneurship is of interest to scholars and practitioners in technical communication for at least two reasons. The work that is variously attributed to social entrepreneurship above is already within the field's research and teaching interests. Furthermore, it represents an opportunity to develop interdisciplinary responses to complex social issues.

This experience report provides an account of an experiment in project-based social entrepreneurship at an undergraduate-focused liberal arts institution. Students and faculty from across multiple disciplines collaborated with experts in the private sector to create attachments or modifications to Unmanned Aerial Vehicles (UAVs, commonly known as drones) for social entrepreneurship purposes. Using open-coded student reflection papers and faculty feedback, the report assesses the efficacy of the communications design that informed the project and suggests how it can be 
improved. To conclude, the report gestures to the importance of communication design in sustainable social entrepreneurship education.

\section{ABOUT THE PROJECT}

The project was not grounded in a single, specific course, even if the team of faculty and students met weekly in the same space, perused the same content, and responded to the same assignments. Rather, it was comprised of three elective courses from three disciplines: my "Writing in the Community" course form the School of Writing, Rhetoric and Technical Communication; a special topics course form the Physics department; and an Industrial Design studio course. In addition to these classes, several students chose to partake in this course through independent studies. The project was taught by faculty from Physics, Biology, Industrial Design, and Writing Studies in partnership with entrepreneurs who make commercial products for UAVs. These entrepreneurs (who are also founding members of NOVALabs, a volunteer maker-space in Reston, Virginia) mostly contributed to the class via telepresence robots. The entire project was supported by 4-VA, a state-wide initiative in Virginia with the mission of building collaborative teaching, collaborative research, and a culture of entrepreneurship across the four major universities in Virginia.

The goal of the project was to teach students how to bring an idea from concept to working prototype. No single disciplinary perspective dominated, and students were assigned to crossdisciplinary teams from the very beginning. Each team was asked to collectively locate and research a pressing or ecological issue that might benefit from the use of UAV technology. Once the teams decided on projects, they began a design process that harnessed their available time, skills, and resources to make a prototype of a practical intervention to their chosen problem. Due to shifting policies in the Federal Aviation Authority regarding the use of drones in educational contexts, final projects were largely theoretical, as we were unable to obtain flight licenses to test the student designs.

The project took place in a well-equipped maker space (a lab setting with object fabrication tools). Students also had access to a design studio in the Industrial Design department. Between both spaces, students could make use of a variety of professional-grade tools: 3D printers; CNC (Computer Numerical Control) machines that facilitate precision fabricating controlled by computers; thermoforming technologies (which create precise, plastic molds), a variety of professional-grade woodshop tools; and large bay inkjet printers capable of printing to large paper and vinyl sheets. Students also had at their disposal six drones that were constructed by Physics majors the previous semester, many of whom also enrolled in our course.

Following a design process methodology [4], the semester was divided into phases that focused on research, prototypying, testing, and refining. By the end of the semester, the six student teams produced attachments for the drones that sought to: detect landmines; dispose of landmines; track the circulation of a specific type of atmospheric air pollutant; detect a rare mussel in sandy riverbeds; create 3D models of historic buildings; and investigate the use of UAVs to transport medicine to remote regions. The course concluded with a public exhibition of the projects, which was attended by over 100 people from our campus, the local community, and other universities in the region.

\section{THE ROLE OF WRITING IN THE PROJECT}

Throughout the semester, the students produced writing and multimedia artifacts for the purposes of project development, documentation of student learning, and promotion of the project to audiences on campus and other interested stakeholders. Process documentation that captured the students' research was published internally to a Google Drive account and Canvas, our university's Learning Management System (LMS). Files posted to these platforms were only available to the faculty and students taking the course. A publicly available WordPress site hosted on our university's servers represented the public face of the course, and contained ten posts by each of the six student teams that documented the process of their research, challenges and successes they encountered along the way, and descriptions of the final prototypes. Finally, teams designed custom-built displays to showcase the prototypes in a public exhibition of their work. These stands included the prototype, written and multimedia materials that explained the problem each team students were responding to, and how their prototype addressed those problems. The following sections account for how each of these platforms were used in the project and how we hope to revise and hone their use in future semesters.

\subsection{Google Drive and Canvas}

The instructors asked student teams to create an archive of all of their process documentation in the form of research, meeting notes, correspondence emails, and "pitch" slides presented in class and revised extensively throughout the course. Each of the teams were responsible for placing these materials in a Google Drive folder. In addition, the instructors used the university learning management system to host course documents, give homework assignments, and communicate with the course members.

Feedback from the students and faculty revealed that the Google Drive was extremely useful as a way to archive project development. Most project members valued having a common space to share files, images, and other artifacts relating to the project: it provided easy access to documents where they needed it, and provided a space where they could see the project developing.

However, Google Drive wasn't without its hassles. We opened a project-specific account, and there were initial problems getting so many people access to the platform. Not all the teams were as rigorous about documenting their process as others, and the documentation process was haphazard at times. Students and instructors alike complained in their final reflections that it was difficult to find materials quickly as not all groups paid attention to file naming and creating subfolders for easy retrieval. Google Drive inhibited full documentation of the course. Many of the groups used messaging platforms such as Facebook groups or GroupME to coordinate their efforts outside of class, but it seemed counterintuitive and awkward to log all those conversations within GoogleDrive. As a result, a large amount of valuable data was missing from many of the teams' GoogleDrive folders.

The responses to the use of the university's LMS were also mixed. From the instructors' point of view, it provided a space to host the project documents, easily send announcements to the class, and to streamline the grading process. But it wasn't always used consistently; sometimes homework and announcements were 
posted through alternative means such as email or in-class announcements. Initially, this created some frustration among the students about where they should go for certain information. Another issue was that our class had several collaborators who are not part of the university system, and LMSs, though useful for running classes, are not always intuitive to people outside the education system who have not used them before.

Future iterations of the course could certainly streamline this internal documentation using the LMS and Google Drive. We will continue to use a course LMS as a place to streamline the grading process for the course. Since LMSs are not open to the public, they are useful for students to practice communication strategies that are useful in professional contexts. As John M. Spartz argues, LMSs can also be productively used as a safe space to allow students to practice writing narratives that help them to cultivate an entrepreneurial ethos [7]. The LMS could therefore be used as a drafting space where student teams cultivate their public voice before they publish to the course blog and social media sites.

We also plan to continue using Google Drive as a space to store project activity for each of the groups. In order to fully capture the activity of student group, however, we plan to include popular project management tools to our suite of communications platforms. For internal group communications, we will ask students to exclusively use Slack, a messaging system that is increasingly used in business, and Trello, a popular web-based project management tool. These platforms are all inter-operable with each other and connect with services such as Google Drive for file management and sharing. Focusing internal group communications in this manner will provide instructors with a granular understanding of how groups communicate as projects evolve. Furthermore, this approach has the benefit of introducing students to the kinds of project management platforms that they are likely to encounter in the workplace.

\subsection{The WordPress Blog}

In addition to the internal process documentation, students to craft blog posts for a publicly accessible WordPress website (http://sites.jmu.edu/jmudroneschallenge/). Each team posted ten short articles, which are accessible via links on the navigation bar on the site that were dedicated to each team. Topics posted to the blog included reflections on the teams' research process, experience of collaboration, and the challenges of doing designdriven social entrepreneurship work. Teams posted process documentation that would be of interest to a broader audience, such as the pitch slides each team's bill of materials (the list of purchases the teams made to construct their prototypes). The goals of these writing prompts were to foster collaboration (teamwritten posts were actively encouraged); promote the final showcase of student work at the end of the semester; and to create a public archive that documented the journey of the entire class.

Easily-learned (and mostly free) publishing technologies enabled students to create multimedia blog posts. Teams used Timeline JS to create an interactive timeline of their projects; an online service called ThingLink allowed students to create annotated images that labelled the various parts of the attachments they created for the drones. Students also had access to Videolicious, a video editing platform designed to easily create and edit newscasts-style video clips on mobile devices. In addition, students used the Adobe Creative Suite graphics packages such as In-Design as well as simpler, web-based graphics platforms such as Canva to create posters that were also published to the blog and used for the final presentation.

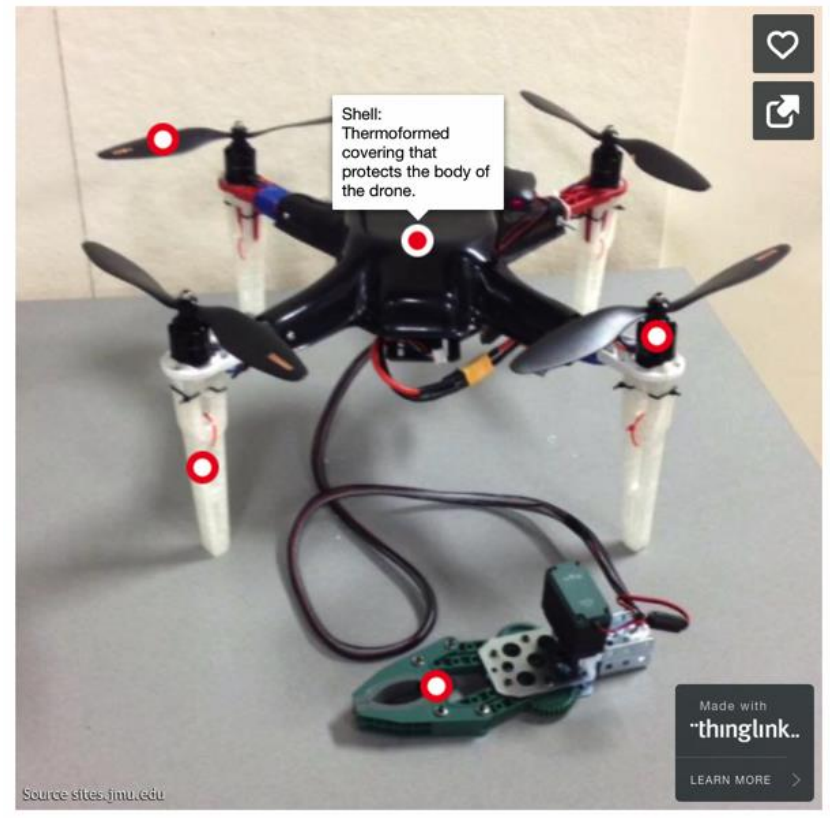

Figure 1. Annotated image of project prototype on the course website. Using a mouse, readers can hover over each of the circles to learn more about the constituent parts of the prototype.

The WordPress website received overwhelmingly positive reviews in both the student and faculty feedback. Nearly all thought that it presented a valuable public archive of the work, and a practical way to document the course in students' online portfolios. The public aspect of the communication allowed for interested parties beyond the class to interact with the process of the groups. A notable example of such interactions was when a United Nations landmine special interest group circulated the work on landmine mine detection and detonation on their international listserv.

This public face of the project also received positive reviews from students and faculty alike for promoting interdisciplinary research. The weekly posts provided a context where teams had to strive to explain technical concepts in a manner understandable for different audiences through the use of different genres and multimedia treatments. The website provided a focus for writing studies students who had less technical expertise than those in other disciplines. Students for whom writing was not typically a major component of their course work were excited to see their research documented in such an accessible fashion, as they had little opportunity to do this kind of work in their disciplinespecific classes.

Feedback from faculty and students indicates that posting to the website can be improved in later iterations of the course. The website was not published until the last few weeks of the semester - publishing student work earlier may well lead to more interactions with interested parties beyond the course. Publishing earlier will require a more systematic editing process; the task of editing student posts fell to the faculty member and a designated student editor, which created a bottleneck in getting work to a publishable level quickly and efficiently. Developing a system 
where individual teams edit each other's work on a weekly basis may help to get student work to the web in a more timely fashion.

The specificity of the posts could also be improved; feedback indicated that writing prompts were sometimes vague and not as timely as they could have been. A fruitful direction for the next iteration of the class would be to form prompts that ask students to better articulate the complexity of the social entrepreneurial journey. Pache and Choudrey argue that social entrepreneurs must negotiate several, overlapping systems such as grassroots organizations, and governments and public agencies [7]. Asking students to articulate how they appeal to these constituencies, and how those appeals inform the design process, will be valuable for students' understanding of the emergent, complex nature of designing for entrepreneurial contexts.

Student and faculty feedback clearly point to another way to focus blog post prompts. Students were both impressed and surprised with the ease and speed that Industrial Design majors on each team were able to create prototypes using 3-D printing and plastic manipulation tools. Many students from other majors were not even aware that such processes were possible on a university campus. Asking teams to write focused blog posts about how these tools operate and contribute to the design process can help to educate the teams about technical prototyping processes, as well as reveal to broader audiences about how student work in higher education can create sophisticated solutions to technical and design challenges.

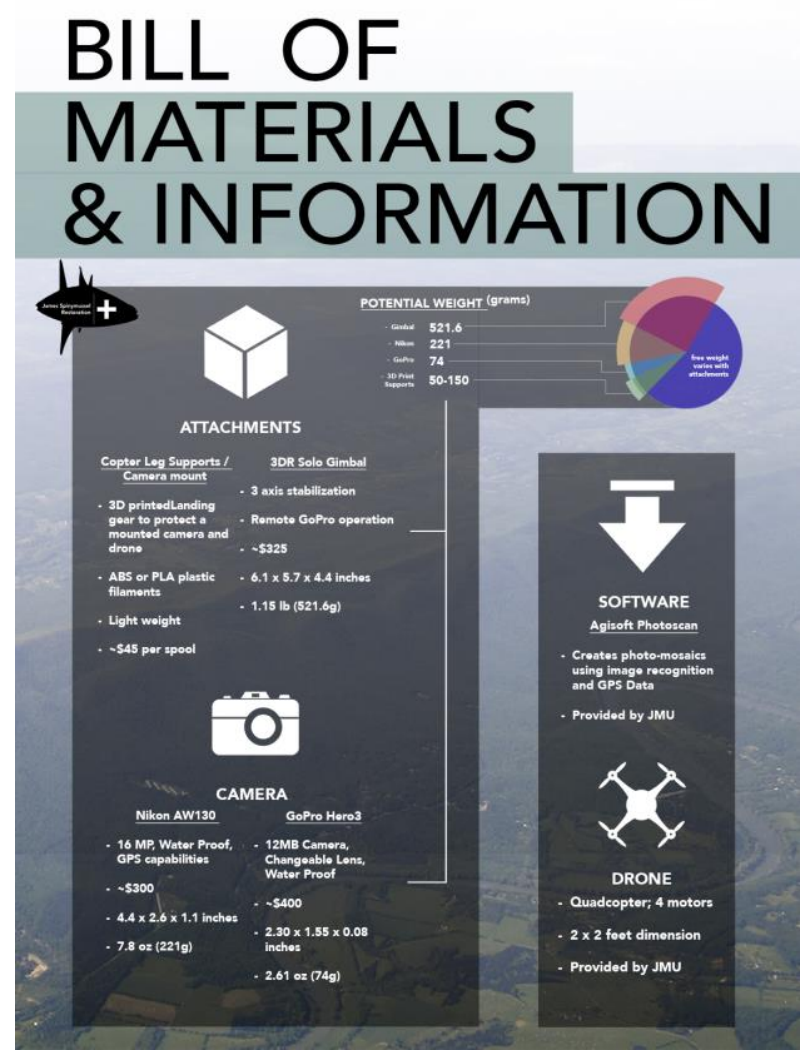

Figure 2. A Bill of Materials document rendered as an infographic and posted to the course website.

Sophisticated articulation of technical processes for broader audiences fits well with the emerging methodologies in technical communication. New materialist approaches ask us to more persuasively account for nonhuman processes in communication design by more carefully documenting the agency of nonhuman objects in the design process, rather than just representing them as merely the tools of human will and ingenuity. As McNely, Spinuzzi, and Teston argue,

scholarship in the material turn has troubled how researchers should bound off and study objects and practices, given the potentially formidable roles such objects and material environs play in everyday work and in practical attunements of technical communicators to those environs. [3]

Bringing new materialist ideas to writing prompts may benefit students in helping them to better articulate the relationship between humans, materials, objects, and processes in product development with a social entrepreneurial focus.

McNely and Rivers [4] propose a variety of new materialist pedagogical tactics that could be productively adapted to the next iteration of the course. For example, the authors suggest that carefully detailing task environments, listing potential human and nonhuman actors that might respond to a design problem (and treating those actors equally) might help to better illuminate how how the design process works. Such heuristics could be easily adapted to blog post prompts and other kinds of assignments for future iterations of the course.

\subsection{The Final Showcase}

Indeed, perhaps the most realized version of a new materialist approach to communication design in the first iteration of the course was the final showcase for the students' projects. Each team designed custom stands to present their prototypes, which included the drone and its attachment, posters, lighting effects, and touch screens. The more successful projects incorporated the project's theme into the design of the stand itself. For example, the group that investigated how to locate, map, and predict river habitats that support the James Spinymussel created a large table that was in the shape of the mussel, upon which facts about the project were written onto $3-\mathrm{D}$ printed shells that were buried into the sand on the table top for the audience to find and read.

The showcase provided an excellent example of how an interdisciplinary approach to communication design can align written discourse with material fabrication, lighting, and other design elements. The stands incorporated texts and graphics for other documents on the website; the bill of materials and pitch slides for each group became part of the final presentation. As such, preparation for the final showcase helped to reinforce the students' commitment to interdisciplinary practice, as students from technical disciplines, writing studies, and industrial design had to work closely together to build the final presentation.

Considering that social entrepreneurship projects are likely to be focused on specific local audiences, the showcase provided students with a sense of how various kinds of documentation can be can be repurposed for a specific physical space and live event. Because the groups in this iteration of the course were not designing with specific clients in mind, the public showcase also provided students with a real and tangible audience to focus their efforts as the end of the semester to came into view. The event attracted family members of the students who were part of the project, other students, faculty, and members of the upper administration in our university, as well as faculty from other universities in the 4-VA network attended. Feedback from students' final reflections strongly suggest that the showcase was 
particularly important to their sense of accomplishment, as it gave the student teams an opportunity to argue for their prototype's value to a fresh audience who were unaware of the necessary trials and tribulations involved in this kind of design work.

\section{CONCLUSION}

Faculty are already involved in designing the next iteration of this approach to project-driven social entrepreurship education for the Fall 2016 semester. It is difficult to bring projects beyond the prototype stage within the short time frame of the semester. Consequently, we plan to build on the more successful projects built by students in the initial course, in the the hope students in the next offering might achieve more realized prototypes that might attract market interest or further research fuding.

We are also revising many of the teaching methods we tested in the initial course, many of which have sown seeds for further projects, in the 4-VA network and internationally. As described elsewhere in this report, we plan to revise the communications design by building more effective project management tools to help students to manage and report on their projects. Better use of the LMS will help students to test different ways to communicate their progress and process to diverse audiences beyond the confines of the class. More focused and better timed blog posts, as well as a more comprehensive editing process editing process for those posts, will enable students to clearly articulate their design process for non-technical audiences.

Beyond these revisions, this course has taught faculty is that communication design communication design is an important part of the operating system upon which experimental interdisciplinary social entrepreneurship runs. Process documentation serves the important pedagogical and project management purposes for student groups. Composing for public audiences provides students with a sense of how to better articulate the issues they are responding to and how they are designing for those issues. Public events bring together key stakeholders and also help to further promote interdisciplinary social entrepreneurship practices on a higher education campus. Without an expansive understanding of how communication design informs and transforms social entrepreneurship, students and faculty will be less well equipped to translate ideas and processes from across the disciplines, and to apply them to complex and pressing problems to which social entrepreneurship is increasingly being called upon to respond.

\section{REFERENCES}

[1] Choi, N. and Majumdar, S. 2014. Social entrepreneurship as an essentially contested concept: Opening a new avenue for systematic future research. Journal of Business Venturing. 29, 3, 363-376. DOI=10.1016/j.jbusvent.2013.05.001.

[2] Howorth, C., Smith, S. M., and Parkinson, C. 2012. Social Learning and Social Entrepreneurship Education. Academy of Management Learning \&amp; Education. 11, 3, 371-389. DOI=10.5465/amle.2011.0022.

[3] McNely, B., Spinuzzi, C., and Teston, C. 2014. Contemporary Research Methodologies in Technical Communication. Technical Communication Quarterly. 24, 1, 1-13. DOI=10.1080/10572252.2015.975958.

[4] McNely, B. J. and Rivers, N. A. 2014. All of the things: Engaging complex assemblages in communication design. Proceedings of the 32nd ACM International Conference on The Design of Communication. 7.

[5] Pache, A.C. and Chowdhury, I. 2012. Social entrepreneurs as institutionally embedded entrepreneurs: Toward a new model of social entrepreneurship education. Academy of Management Learning \&amp; Education. 11, 3, 494-510.

[6] Purdy, J. 2014. What Can Design Thinking Offer Writing Studies? College Composition and Communication. 65, 4, 612 - 641.

[7] Spartz, J. M. 2010. Rhetorical Savvy as Social Skill: Modeling Entrepreneur Identity Construction within Educational Content Management Systems. Writing Instructor. 